\title{
Thermographic follow-up of postherpetic neuralgia (PHN) subsequent to Ramsay Hunt syndrome with multicranial nerve $(V$, VII, VIII and IX) involvement: a case report
}

Yuan-Mei Liao ${ }^{1 \dagger}$, Hai-Feng Lü ${ }^{2 \dagger}$, Peng Xie ${ }^{3 \dagger}$, Ying Zhao ${ }^{4}$, Qiu Han ${ }^{5}$, Qian-Xi Zhang ${ }^{7}$, Xiao-Hua Zuo ${ }^{6,7^{*}}$, Yan-Na Si ${ }^{6}$ and Hong-Guang Bao ${ }^{6}$

\begin{abstract}
Background: Ramsay Hunt syndrome (RHS) is caused by a reactivation of varicella-zoster virus (VZV) infection, and it is characterized by the symptoms of facial paralysis, otalgia, auricular rash, and/or an oral lesion. Elderly patients or immunocompromised patients, deep pain at the initial visit and no prompt treatment are significant predictors of postherpetic neuralgia (PHN). When PHN occurs, especially involved cranial polyneuropathy, multiple modalities should be administered for patients with the intractable PHN. The use of thermography in the follow-up of PHN secondary to RHS with multicranial nerve involvement has not yet been described yet in the literature.

Case presentation: The patient was a 78-year-old man with the chief complaint of a 3-month history of PHN secondary to RHS with polycranial nerve $(\mathrm{V}, \mathrm{VII}, \mathrm{VIII}$, and IX) involvement. Multimodality therapy with oral gabapentin, pulsed radiofrequency (PRF) application to the Gasserian ganglion for pain in the trigeminal nerve region, linear-polarized near-infrared light irradiation for pain in the facial nerve region, and $2 \%$ lidocaine spray for pain in the glossopharyngeal nerve region was used to the treat patient, and follow-up evaluations included thermography. This comprehensive treatment obviously improved the quality of life, resulting in considerable pain relief, as indicated by a decrease in the numerical rating scale (NRS) score from 9 to 3 and a decrease in thermal imaging temperature from higher to average temperature on the ipsilateral side compared with the contralateral side. Lidocaine spray on the tonsillar branches of the glossopharyngeal nerve resulted in an improvement in odynophagia, and the NRS score decreased from 9 to 0 for glossopharyngeal neuralgia after three applications.

(Continued on next page)
\end{abstract}

\footnotetext{
* Correspondence: xiaohuazuo@yahoo.com

${ }^{\dagger}$ Yuan-Mei Liao, Hai-Feng Lu and Peng Xie contributed equally to this work.

${ }^{6}$ Department of Anesthesiology, Nanjing First Hospital, Nanjing Medical

University, Nanjing 210006, China

${ }^{7}$ Department of Pain Management, The Affiliated Huai'an Hospital of Xuzhou

Medical University and The Second People's Hospital of Huai'an, Huai'an

223002, China

Full list of author information is available at the end of the article
}

(C) The Author(s). 2021 Open Access This article is licensed under a Creative Commons Attribution 4.0 International License, which permits use, sharing, adaptation, distribution and reproduction in any medium or format, as long as you give appropriate credit to the original author(s) and the source, provide a link to the Creative Commons licence, and indicate if changes were made. The images or other third party material in this article are included in the article's Creative Commons licence, unless indicated otherwise in a credit line to the material. If material is not included in the article's Creative Commons licence and your intended use is not permitted by statutory regulation or exceeds the permitted use, you will need to obtain permission directly from the copyright holder. To view a copy of this licence, visit http://creativecommons.org/licenses/by/4.0/ The Creative Commons Public Domain Dedication waiver (http://creativecommons.org/publicdomain/zero/1.0/) applies to the data made available in this article, unless otherwise stated in a credit line to the data. 


\begin{abstract}
(Continued from previous page)
Conclusion: Although the use of thermography in the follow-up of RHS with multiple cranial nerve $(\mathrm{V}, \mathrm{VII}, \mathrm{VIII}$, and IX) involvement is very rare, in this patient, thermal imaging showed the efficacy of combination therapy (oral gabapentin, 2\% lidocaine sprayed, PRF application and linear-polarized near-infrared light irradiation) and that is a good option for treatment.
\end{abstract}

Keywords: Postherpetic neuralgia (PHN), Ramsay Hunt syndrome, Multiple cranial nerves, Linear-polarized nearinfrared light, Infrared thermography

\section{Background}

Ramsay Hunt syndrome (RHS) is a multicranial neuropathy caused by the varicella-zoster virus (VZV) infection, and it is characterized by the symptoms of facial paralysis, otalgia, auricular rash, and/or an oral lesion [1, 2]. Correct diagnosis and subsequent proper treatment can reduce the incidence of postherpetic neuralgia (PHN), which may lead to significant physical, occupational, and social impairments due to the unceasing pain [3]. Elderly patients or immunocompromised patients, deep pain at the initial visit or a lack of proper therapy at the beginning of the illness are significant predictors for PHN [4]. When PHN occurs, especially involved cranial polyneuropathy, multiple modalities should be administered for patients with intractable PHN.

To monitor the response to treatment in patients with PHN, infrared thermography (a noninvasive medical diagnostic tool for analysing the physiological function of the sensory nervous system, autonomic nervous system, and local and systemic inflammation) is used to study the physiology of thermoregulation and reveals a correlation of thermal imaging with the intensity of pain. Infrared thermography has been shown to quickly detect someone's surface skin temperature without being physically close to the person being evaluated for the duration of the public health emergency related to coronavirus disease 2019 (COVID-19) [5]. Previously, studies were performed on RHS associated with multiple cranial nerves (CN IV, CN V, CN VII-XI, and cervical nerves $\mathrm{C} 2$ - C3) $[6,7]$, and thermographic follow-ups in herpes zoster and PHN $[8,9]$. Nevertheless, PHN secondary to RHS associated with multicranial nerve $(\mathrm{CN}$ $\mathrm{V}, \mathrm{CN}$ VII, CN VIII, and CN IX) involvement and follow-up with infrared thermal has not yet been described yet in the literature. In this paper, the improvement in PHN after comprehensive treatment was evaluated according to the NRS score and infrared thermography.

\section{Case presentation}

A 78-year-old man with the a chief complaint of a 3month history of gradually increasing pain and numbness in the right ear, submandibular region, temporal region, and the right side of the tongue root and rightsided facial weakness was seen (Fig. 1). Paroxysms of odynophagia triggered by swallowing lasted throughout mealtime. Depending on swallowing and stress, the pain intensity was rated a 9-10 on the numerical rating scale (NRS). The patient had been almost unable to take any food for several days. He complained of otalgia and hot flashes on the right side of the face and ear. He had not had symptoms of vertigo, tinnitus, nausea, or vomiting. Peripheral facial paralysis was classified as HouseBrackmann grade III. The results of the audiogram were normal. Laboratory investigations and brain magnetic resonance imaging (MRI) were unremarkable. Medical therapy began with the application of ipsilateral lidocaine spray to the tonsillar branch of the glossopharyngeal nerve before mealtime. The second day after three lidocaine sprayed applications, the patient's odynophagia intensity decreased from a score of 9 to 0 rating on the NRS. The recommended dosage was adjusted according to the response, gabapentin was initiated at a dose of $300 \mathrm{mg}$ once daily, and then the dosage was increased by $300 \mathrm{mg}$ every day until a therapeutic dose $(600 \mathrm{mg}$ three times daily) was reached.

The delivery of pulsed radiofrequency (PRF) to the Gasserian ganglion was recommended to alleviate the pain of the mandibular nerve division of the trigeminal nerve. A radiofrequency generator (ET-20S, Smith \& Nephew, Massachusetts, USA) was inserted through the foramen ovale into Meckel's cave under common fluoroscopic control guided by bony landmarks (Fig. 2). Sensory testing at $50 \mathrm{~Hz}$ and motor testing at $2 \mathrm{~Hz}$ were performed to determine whether the needle was on the sensory target. The PRF was thermally coagulated at $42^{\circ} \mathrm{C}$ for $120 \mathrm{~s}$, at two bursts per second of 20 milliseconds duration. The first PRF application to the Gasserian ganglion produced some pain relief; then, the second PRF application to the Gasserian ganglion was performed a week later. Pain intensity was correlated with thermal imaging. Infrared thermography of the treated pain area did not reveal a higher temperature than that of the contralateral side at one week, one month, or three months (Fig. 3b; c; d; f); Thermographic findings of the pain area showed a higher temperature than that of the contralateral side at three months when a dose of gabapentin was missed (Fig. 3e), whereas thermography showed a lower temperature image after gabapentin administration. 


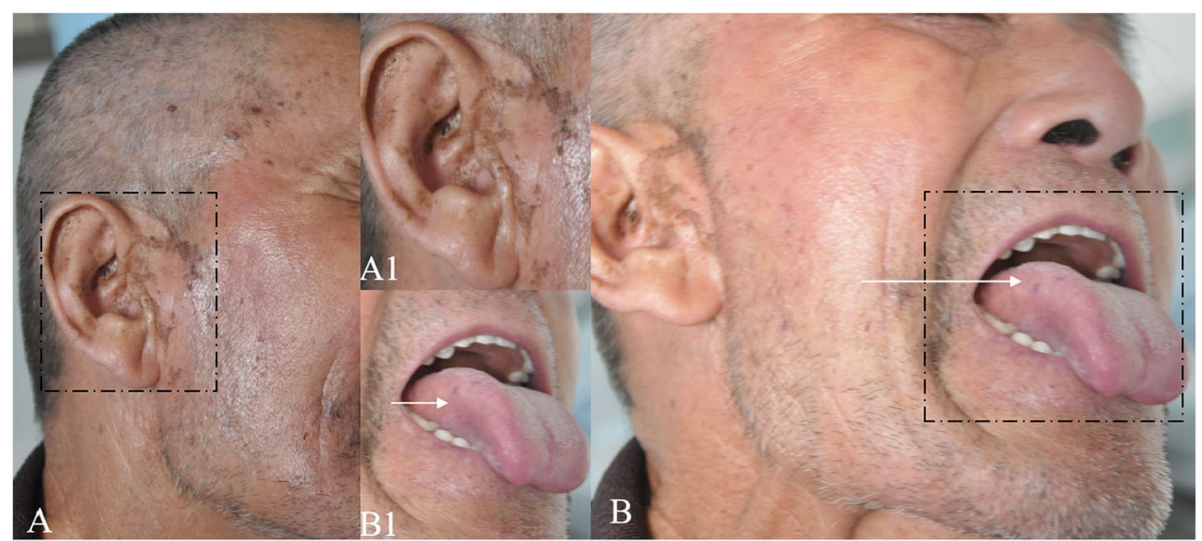

Fig. 1 The Patient exhibited a herpes zoster scar of the right auricle (A, A1), right temporal region (A), and right side of tongue root (B, B1, arrow)

Peripheral facial paralysis was treated with linearpolarized near-infrared light irradiation [10] (MINATO ALB-200H, Minato, Japan) under the following conditions: a power of $1.4 \mathrm{~W}$, a cycle of $1 \mathrm{~s}$ on and $3 \mathrm{~s}$ off; and a duration of $10 \mathrm{~min}$, once a day, and ten times in all. The House-Brackmann grade at one month indicated that the patient was healthy. The lesions were followed up by thermogram (IRIS-5000, Medicore, Seoul, South Korea) during combined therapy and after one week, one month and three months.

Written informed consent was obtained from the patient for the publication of this case report and accompanying images.

\section{Discussion and conclusion}

RHS with simultaneous involvement of multiple cranial nerve ganglia (the geniculate ganglion and peripheral ganglia of cranial nerves VIII, IX, and X) caused by VZV infection and its subsequent activation may cause herpes zoster cephalicus, facial paralysis, otalgia, an auricular rash and/or an oral lesion [11]. In 1915, Sharpe classified herpes zoster cephalicus into five categories based on the inflammation of the geniculate, auditory, glossopharyngeal or vagal ganglia with or without concomitant facial and acoustic symptoms [11]. Hunt's original description in 1907 included only the inflammation of sensory ganglia of the cranial nerves CNVII, CN VIII, CN IX, and CN X. The original description did not adequately address the polyneuropathic pathogenesis or outlined classification of this syndrome, for example, central (CN V, CN IX, CN X, $\mathrm{CN}$ XI, and CN XII), cervical (spinal nerves $\mathrm{C} 2$ and $\mathrm{C} 3$ ) and peripheral nerves were not included in the original description and nor was a description of the coinvolvement cranial nerves. Although the mechanism of this involvement remains unclear, there are three common hypotheses to explain this relationship. First, in the embryological and anatomical correlation hypothesis, the vestibulocochlear nerve is located near the Geniculate ganglion within the bony facial canal; therefore, inflammation in a single ganglion could spread in a chain-like manner to adjacent ganglia, including the Gasserian, geniculate and other cranial and second/third cervical ganglia. Second, in the vasculitis hypothesis, contiguous cranial neuropathies may be partly due to the selective vulnerability of blood vessels to varicella-zoster virus and the universal blood supply. Finally, in the brainstem reflex
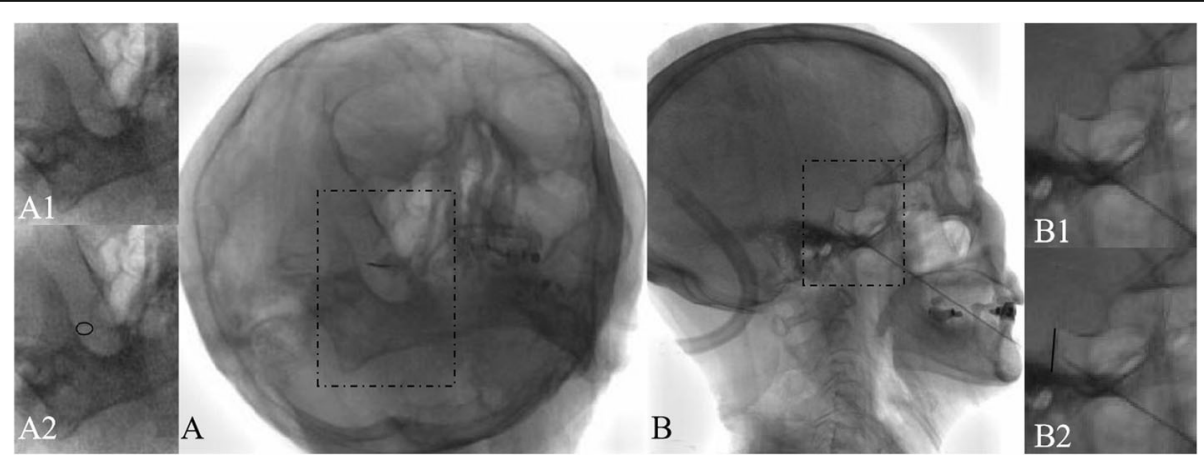

Fig. 2 Under $C$-arm guidance, the needle is safely advanced until its tip is positioned in the foramen ovale anteroposterior $(A, A 1, A 2)$ and equal to the lateral clivus (B) lateral 


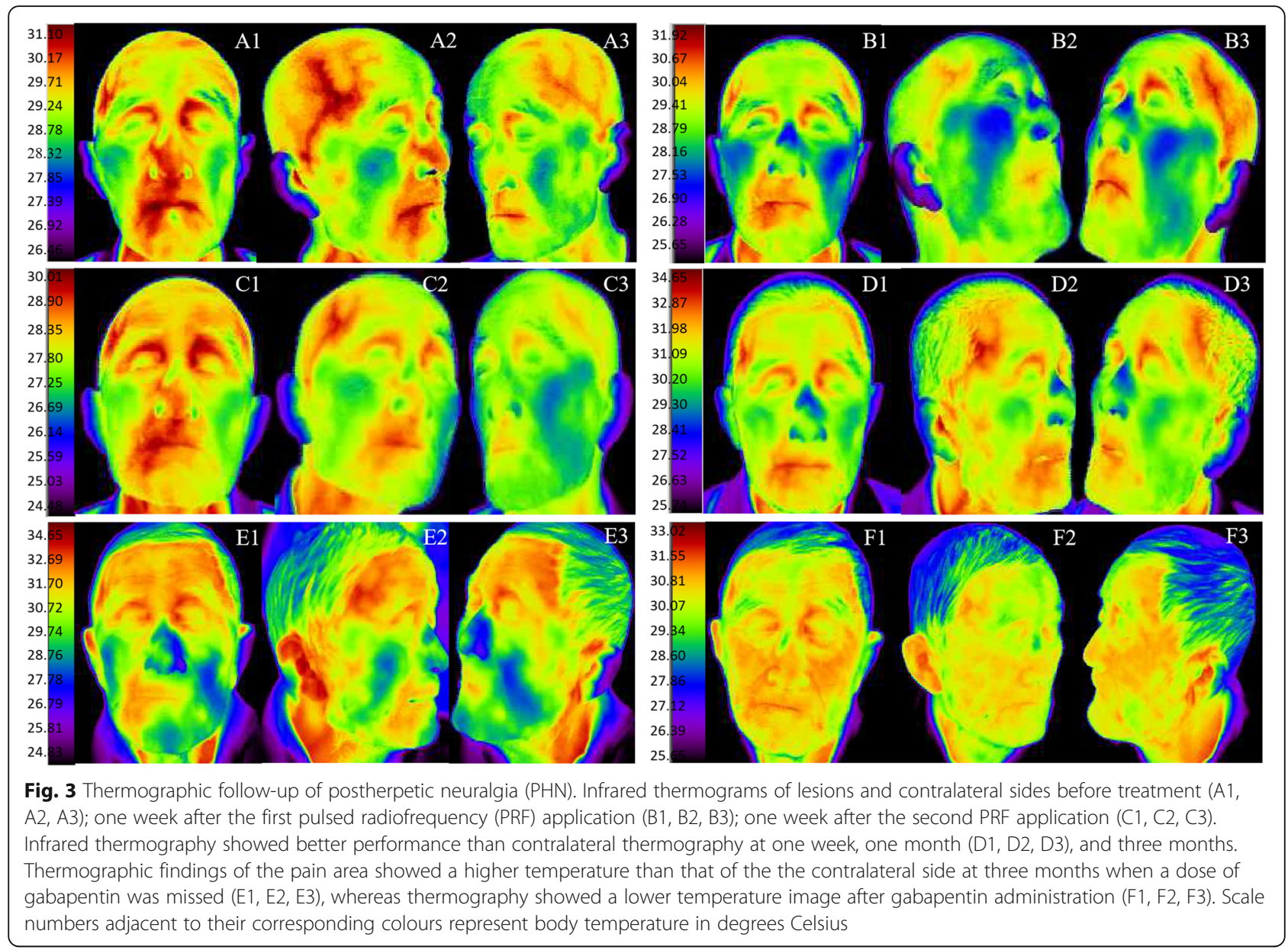

pathways hypothesis, VZV is hypothesized to spread along brainstem reflex pathways through an intersynaptic transmission, mainly in an anterograde direction, resulting in cranial polyneuropathy [12].

When PHN occurs, resulting in severe physical, occupational, and social impairments due to unceasing pain, combination therapy should be administered to patients with intractable PHN. First, the application of lidocaine spray to the tonsillar branches of the glossopharyngeal nerve resulted in complete resolution of the lateral glossopharyngeal neuralgia due to Eagle's syndrome [13]. Topical therapeutic approaches produce lower systemic concentrations, which result in fewer systemic side effects and drug-drug interactions. Lidocaine is a local anaesthetic that modulates pain by blocking the transmission of impulses in peripheral nerves through the blockade of voltage-gated sodium channels [14]. Topical anaesthetics can also suppress the phosphorylation of extracellular signal-regulated kinases (ERKs) in the dorsal horn of the spinal column, which plays a critical role in signal transduction of the pain pathway $[15,16]$. The use of topical anaesthetics could relieve the pain of neuropathic pain or pain of PHN through a combination of central and peripheral nervous system actions [17]. Treatments for postherpetic (glossopharyngeal) neuralgia include the application of local lidocaine sprays rather than the invasive treatment, which can lead to arterial hypotension, neuritis, deafferentation pain, neurovascular injury, and severe haemodynamic problems [18]. Noninvasive local anaesthetics sprays should be considered as one of the alternative treatments (more than a diagnostic test for the glossopharyngeal neuralgia) for glossopharyngeal neuralgia caused by herpes zoster. Our results showed that lidocaine spray application on the tonsillar branches of the glossopharyngeal nerve resulted in the relief from odynophagia, and the NRS score decreased from 9 to 0 for the glossopharyngeal neuralgia after three applications. A glossopharyngeal neuralgia patient relieved pain by using topical lidocaine sprayed before mealtime for six years. Second, linear-polarized near-infrared light irradiation has both light chemical and thermal effects on the neuromuscular system and alleviates pain, and it has some advantages, such as its noninvasiveness, easy and straightforward operation, and shorter time per treatment session than electrogalvanic stimulation [19]. This therapeutic modality, sometimes substituted for invasive treatment in patients, has been used effectively to treat painful 
disorders, such as temporomandibular joint pain, frozen shoulder, osteoarthritis, rheumatoid arthritis, thalamic pain, complex regional pain, intractable anorectal pain, and PHN [20]. Linear-polarized near-infrared light irradiation is an important treatment modality for patients recovering from Bell's palsy (neuronal recovery and maintaining facial muscle tone), and it stimulates the peripheral nervous system resulting in vasodilation, muscle relaxation and the normalization of the autonomic nervous system [10, 21]. Our results showed that the House-Brackmann score changed to Grade I at one month following linear-polarized near-infrared light irradiation.

Infrared thermography was used to study the physiology of thermoregulation and revealed a correlation of thermal images with the intensity of pain [9]. Warm spots observed via infrared thermography reflect inflammation as a result of histamine or substance P secretion, whereas cold spots reflect sympathetic nerve activity and sweating. When combination therapy is prescribed, the right-sided infrared thermographic image of the pain region did not show a higher temperature than the thermographic image of the contralateral side at one week, one month, and three months; therefore, thermography might be a useful tool to objectively assessment tool of subjective pain symptoms in patients with PHN. The first PRF application to the Gasserian ganglion produced some pain relief; then, the second PRF application to the Gasserian ganglion was performed a week later. Pain intensity was correlated with thermal images. The infrared thermogram of the treated area did not reveal a higher temperature than that of the contralateral side at one week, one month, and three months. Especially when a dose of gabapentin was missed, thermographic findings showed a higher temperature in the pain zone than in the contralateral side at three months. Patient treatment can be adjusted according to infrared thermographic findings and the NRS score. Gabapentin should not be stopped abruptly; it should be reduced gradually over a minimum of one week [22].

This comprehensive treatment improved the quality of life, provided considerable pain relief, and showed a correlation of thermal images with the intensity of pain. Further prospective investigations might be needed to estimate the effectiveness of comprehensive treatment for polycranial nerve PHN secondary to RHS with multicranial nerve (CN V, CN VII, CN VIII, and CN IX) involvement.

\footnotetext{
Abbreviations

PHN: Postherpetic neuralgia; RHS: Ramsay Hunt syndrome; VZV: Varicellazoster virus; PRF: Pulsed radiofrequency; NRS: Numerical rating scale;

$\mathrm{CN}$ : Cranial nerve; MRI: Magnetic resonance imaging
}

\section{Acknowledgements}

We are very grateful to Arumai Raja Selvin and the American Journal Experts for editing the English text of a draft of this manuscript.

\section{Authors' contributions}

Design of the work - YM L, HF L, P X; data acquisition and analysis - YM L, HF L, P X; interpretation of data - YM L, QX Z, XH Z; drafting and revision of the manuscript $-Y Z, Q H, X H Z, Y N S, H G$ B. All authors agreed with their authorship and approved the submitted version of the manuscript.

\section{Funding}

This study was funded by the National Natural Science Foundation of China (No. 81873954).

\section{Availability of data and materials}

The datasets used and/or analysed during the current study are available from the corresponding author upon reasonable request.

\section{Ethics approval and consent to participate}

We confirm that we have read the journal's position on issues involved in ethical publication and affirm that this report is consistent with these guidelines. As this is a case report describing clinical observations, ethics approval was waived.

\section{Consent for publication}

Consent to publish was obtained in written form from the patient. The patient consented to the publication of this case report.

\section{Competing interests}

All authors report no conflict of interest.

\section{Author details}

'Department of Medical Technology, Gannan Healthcare Vocational College, Ganzhou 341000, China. ${ }^{2}$ Department of Radiology, The Affiliated Huai'an Hospital of Xuzhou Medical University and The Second People's Hospital of Huai'an, 223002 Huai'an, China. ${ }^{3}$ Department of Neurosurgery, The Affiliated Huai'an Hospital of Xuzhou Medical University and The Second People's Hospital of Huai'an, Huai'an 223002, China. ${ }^{4}$ Department of Neurology, The Affiliated Huai'an Hospital of Xuzhou Medical University and The Second People's Hospital of Huai'an, Huai'an 223002, China. ${ }^{5}$ Department of Neurology, Huai'an First People's Hospital, The Affiliated Huai'an NO.1 People's Hospital of Nanjing Medical Universtiy, Huai'an 223002, China. ${ }^{6}$ Department of Anesthesiology, Nanjing First Hospital, Nanjing Medical University, Nanjing 210006, China. ${ }^{7}$ Department of Pain Management, The Affiliated Huai'an Hospital of Xuzhou Medical University and The Second People's Hospital of Huai'an, Huai'an 223002, China.

Received: 15 July 2020 Accepted: 21 January 2021

Published online: 28 January 2021

\section{References}

1. Hunt JR. The symptom-complex of the acute posterior poliomyelitis of the geniculate, auditory, glossopharyngeal and pneumogastric ganglia. Arch Intern Med. 1910;1(6):631-75.

2. Hunt JR. On herpetic inflammations of the geniculate ganglion. A new syndrome and its complications. Arch Neurol. 1968;18(5):584-9.

3. Crosbie B, Lucey S, Tilson L, Domegan L, Kieran J. Acute herpes zoster and post herpetic neuralgia in primary care: a study of diagnosis, treatment and cost. Eur J Clin Microbiol Infect Dis. 2018;37(4):627-31.

4. Li D, Sun GH, Sun HZ, Wang YJ, Wang ZP, Yang JP. Combined therapy of pulsed radiofrequency and nerve block in postherpetic neuralgia patients: a randomized clinical trial. Peer J. 2018;6:e4852.

5. Robbins JA, Aragaki A, Crandall CJ, Manson JE, Carbone L, Jackson R, Lewis CE, Johnson KC, Sarto G, Stefanick ML, et al. Women's health initiative clinical trials: interaction of calcium and vitamin D with hormone therapy. Menopause. 2014;21(2):116-23.

6. Hung CW, Wang SJ, Chen SP, Lirng JF, Fuh JL. Trigeminal herpes zoster and Ramsay Hunt syndrome with a lesion in the spinal trigeminal nucleus and tract. J Neurol. 2010;257(6):1045-6.

7. Arya D, Bajaj T, Gonzalez J, Elkin R. Ramsay Hunt syndrome with multiple cranial neuropathy in an human immunodeficiency virus (HIV) patient. Am J Case Rep. 2018;19:68-71

8. Han SS, Jung $\mathrm{CH}$, Lee SC, Jung HJ, Kim YH. Does skin temperature difference as measured by infrared thermography within 6 months of acute 
herpes zoster infection correlate with pain level? Skin Res Technol. 2010; 16(2):198-201.

9. Ko EJ, No YA, Park KY, Li K, Seo SJ, Hong CK. The clinical significance of infrared thermography for the prediction of postherpetic neuralgia in acute herpes zoster patients. Skin Res Technol. 2016;22(1):108-14.

10. Rothschild D, Ng S. The use of phototherapy for Bell's palsy; 2018.

11. Shrape N. Herpes zoster of the cephalic extremity, with a special reference to the geniculate, auditory, glossopharyngeal, and vagal syndromes. AJMS. 1915;149:725-36.

12. Alicandri-Ciufelli M, Aggazzotti-Cavazza E, Genovese E, Monzani D, Presutti L. Herpes zoster oticus: a clinical model for a transynaptic, reflex pathways, viraltransmission hypotheses. Neurosci Res. 2012;74(1):7-9.

13. Kawasaki M, Hatashima S, Matsuda T. Non-surgical therapy for bilateral glossopharyngeal neuralgia caused by Eagle's syndrome, diagnosed by three-dimensional computed tomography: a case report. J Anesth. 2012; 26(6):918-21.

14. Casale R, Symeonidou Z, Bartolo M. Topical treatments for localized neuropathic pain. Curr Pain Headache Rep. 2017;21(3):15.

15. Ngo AL, Urits I, Yilmaz M, Fortier L, Anya A, Oh JH, Berger AA, Kassem H, Sanchez MG, Kaye AD, et al. Postherpetic neuralgia: current evidence on the topical film-forming spray with bupivacaine hydrochloride and a review of available treatment strategies. Adv Ther. 2020;37(5):2003-16.

16. Yanagidate F, Strichartz GR. Bupivacaine inhibits activation of neuronal spinal extracellular receptor-activated kinase through selective effects on ionotropic receptors. Anesthesiology. 2006;104(4):805-14.

17. Zhu JH, Liu J, Shen GY, Zhong TD, Yu X. Comparison of efficacy outcomes of lidocaine spray, topical lidocaine injection, and lidocaine general anesthesia in nasal bone fractures surgeries: a randomized, controlled trial. Med Sci Monit. 2018;24:4386-94.

18. Singh PM, Dehran M, Mohan VK, Trikha A, Kaur M. Analgesic efficacy and safety of medical therapy alone vs combined medicaltherapy and extraoral glossopharyngeal nerve block in glossopharyngeal neuralgia. Pain Med. 2013;14(1):93-102.

19. Liao CD, Rau CL, Liou TH, Tsauo JY, Lin LF. Effects of linearly polarized nearinfrared irradiation near the stellate ganglion region on pain and heart rate variability in patients with neuropathic pain. Pain Med. 2017;18(3):488-503.

20. Huang D, Gu YH, Liao Q, Yan XB, Zhu SH, Gao CQ. Effects of linear-polarized near-infrared light irradiation on chronic pain. Sci World J. 2012;2012: 567496.

21. Kudoh A, Yodono M, Ishihara H, Matsuki A. Linear polarized light therapy improves Bell's palsy. Laser Ther. 1998;10(2):65-9.

22. Chen JJ, Li LY, Chen SR, Chen H, Xie JD, Sirrieh RE, Maclean DM, Zhang YH, Zhou MH, Jayaraman $\mathrm{V}$, et al. The a $2 \delta-1-\mathrm{NMDA}$ receptor complex is critically involved in neuropathic pain development and gabapentin therapeutic actions. Cell Rep. 2018;22(9):2307-21.

\section{Publisher's Note}

Springer Nature remains neutral with regard to jurisdictional claims in published maps and institutional affiliations.

Ready to submit your research? Choose BMC and benefit from:

- fast, convenient online submission

- thorough peer review by experienced researchers in your field

- rapid publication on acceptance

- support for research data, including large and complex data types

- gold Open Access which fosters wider collaboration and increased citations

- maximum visibility for your research: over $100 \mathrm{M}$ website views per year

At $\mathrm{BMC}$, research is always in progress.

Learn more biomedcentral.com/submissions 